\title{
Interview
}

\section{De grote toezichtinterviewestafette - deel 2: AFM}

\section{Goed toezicht is niet uit te drukken in één kernwaarde}

\section{Rein Halbersma en Karin van Wingerde*}

Voor deze editie van het estafette-interview spraken Rein Halbersma en Karin van Wingerde namens de redactie van Tijdschrift voor Toezicht met Hanzo van Beusekom. Van Beusekom trad in juni 2018 toe tot de raad van bestuur van de Autoriteit Financiële Markten (AFM), waarvoor hij eerder tussen 2003 en 2010 ook al werkzaam was. Binnen het bestuur van de AFM is hij verantwoordelijk voor domeinoverstijgend toezicht en voor vernieuwing. Hij ziet het als zijn belangrijkste opdracht om het toezicht van de AFM meer data- en technologiegedreven te maken. Halbersma en Van Wingerde spreken met Van Beusekom onder meer over zijn terugkeer naar de AFM, over de kernwaarden van de AFM en over de uitdagingen waarvoor toezichthouders zich gesteld zien in een toenemende globale en digitale wereld.

Dr. R.S. Halbersma is onderzoekscoördinator bij de Kansspelautoriteit en redactielid van Tijdschrift voor Toezicht. Dr. C.G. van Wingerde is universitair docent criminologie aan de Erasmus Universiteit Rotterdam en als academic research partner verbonden aan de Kansspelautoriteit. Zij is lid van de redactie van Tijdschrift voor Toezicht. Het gesprek vond plaats op woensdag 17 juli 2019. Met dank aan Manar Moussane, tutor Criminologie aan de Erasmus Universiteit Rotterdam die de transcriptie van het interview voor haar rekening nam.

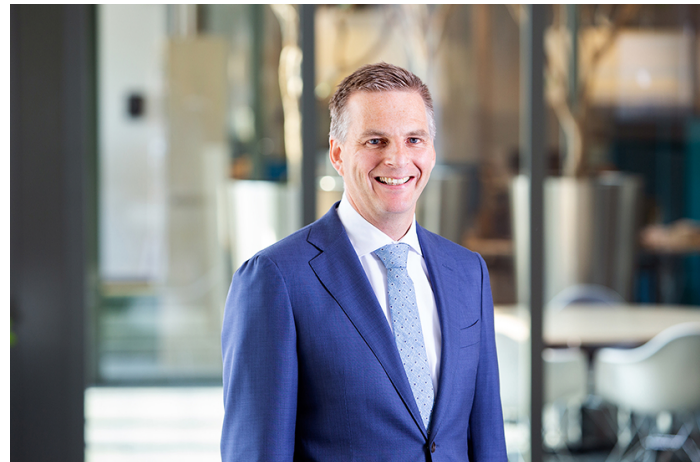

Hanzo van Beusekom (1972) studeerde economie aan de Universiteit van Amsterdam en behaalde een MBA bij INSEAD. Hij begon zijn carrière als consultant bij de Boston Consulting Group en maakte daarna de overstap naar de AFM waar hij in 2003 begon als hoofd strategische analyse en waar hij in 2006 hoofd van de afdeling financieel ondernemingstoezicht werd. In 2010 nam Van Beusekom afscheid van de AFM om zijn eigen adviespraktijk te beginnen. Tussen 2011 en juni 2018 was hij partner van Clear Conduct, een adviesbureau gericht op toezichtvraagstukken. 
Karin en Rein: $U$ bent een tijd lang adviseur gemeest bij veel verschillende toezichthouders en perkt nu in een bestuurlijke executieve functie. Hoe verandert dat um blik, pat heeft u meegenomen en hoe heeft $u$ die omslag meten te maken?

Hanzo: Dat was best wel een grote omslag. Ik ben in 2010 weggegaan bij de AFM en heb acht jaar lang samen met een paar anderen een adviespraktijk gehad. En dat betekent dat je vrij bent, dat je buiten allerlei systemen staat en dat je geen onderdeel uitmaakt van een organisatie. Het was een kleine, maar fijne adviesclub. En dat betekent dat je je vrij vol op de inhoud kan richten en dat je kan nadenken: wat voegt maximale waarde toe, voornamelijk op de inhoud, een beetje op het proces voor de klant voor wie je voor werkt. En die klanten verschillen heel sterk. Dat was een groot aantal markttoezichthouders en inspecties in Nederland en in het buitenland en dat betekent dat je snel van context wisselt, dat je je snel moet verdiepen. En dat betekent dat je ook snel moet begrijpen wat de cruciale uitdagingen voor die organisatie zijn. Dat betekent ook dat ik niet zo heel veel andere belangen had. Dus ik hoefde niet langdurig in die organisatie rond te lopen en dus heb je geen geschiedenis, geen ballast, geen vrienden en ook geen vijanden. En kun je vanuit de buitenkant vragen stellen als: 'Hoe zit dit bouwwerk nou technisch en qua cultuur in elkaar? Waar kan ik aan proberen te draaien om het beter te maken?' En daar kan je best wel scherp in zijn als je wilt. En dat vond ik een hartstikke mooie uitdaging.

Als je dan zelf in een bestuurlijke functie stapt, dan veranderen een paar dingen. In plaats van dat je vanuit de buitenkant kijkt, zit je binnen no time weer in de bubbel en heb je een rol in het systeem. Dus in plaats van dat je aan de buitenkant naast een systeem staat en dit probeert te verbeteren, zit je er opeens in. En je krijgt een vrij invloedrijke rol in het systeem omdat je bestuurder bent.

Dus wat ik meegenomen heb, is mijn blik van 'Wat zie ik nou goed werken en wat kan er beter worden?'. Wat anders is, is dat je vrijheid om te doen en laten wat je wilt anders is. Dus vroeger zou ik gewoon met jullie gepraat hebben en tegenwoordig hebben we er een woordvoerder bij. Vroeger was dit het meest formele wat ik aantrok. [redactie: Van Beusekom was gekleed in een overhemd met nette trui] En nu is dit het minst formele wat ik aanheb. Maar als ik weet dat de ambassadeur van Nederland bij de Europese Unie langskomt, dan denk ik 'Ik moet toch een pak aan en een das om'. Ik ben gewoon een vertegenwoordiger van de AFM en daar hoort een bepaalde houding en opstelling bij, dus dat is anders.

Een ander ding dat veranderd is: mijn status was vroeger onduidelijk, want ik was extern adviseur, consultant. En nu ben ik opeens 'bestuurder' van de AFM, met hoofdletters. Dus dat betekent - terecht of onterecht dat je allerlei status wordt aangemeten. Om een klein voorbeeldje te geven: ik vertel vaak dezelfde voorbeelden, dezelfde verhalen of dezelfde casuïstiek als vroeger en je ziet dat de impact anders is, omdat mensen je woorden zwaarder wegen. Omdat mensen denken 'De bestuurder zegt dat, dus blijkbaar is het zo.' Dat vind ik ook riskant. Dus een van de dingen die ik lastig vind en waar ik over aan het nadenken ben, is feedback. Vroeger kreeg ik heel veel feedback. Als een klant ons werk niet goed vond of onze houding niet goed vond, dan huurde die ons niet meer in. Sterker nog, dat was als het matig was. Als het heel slecht is, dan vertel je het per ongeluk of expres ook nog tegen de buren dat je ons niet moet inhuren. Dat loopt in netwerken rond, dus mijn feedbackfunctie was direct en vrij objectief. $\mathrm{Nu}$ is het indirect en dus ben ik aan het nadenken van hoe organiseer ik m'n feedbackfunctie intern en extern zodat ik nog voldoende prikkels en signalen krijg over wat nu eigenlijk goed gaat. Dat is echt anders als je bestuurder bent dan als je adviseur bent. Je interactie is gewoon dunner en dan zit je in zo'n bestuurscontext met een aparte vleugel en een aparte bestuurskamer. En feedback is altijd biased. Dus ik ben vrij bewust bezig om erover na te denken hoe je dat kan organiseren.

Karin en Rein: Een van de estafettevragen gaat over de vier kernmaarden van de AFM: zorgvuldig en doortastend, autonoom en verbindend. Er zijn vier kernmaarden en hoe die zijn geformuleerd bij de AFM is best uniek. Fullie hebben twee paren naast elkaar. Dus daar zit ook een afruil in, maar melke spreekt $u$ nu het meest aan? Of herkent $u$ het meeste terug?

Hanzo: Het feit dat je twee koppels hebt; dus niet alleen doortastend, maar ook zorgvuldig en dat je niet alleen autonoom bent, maar ook verbindend. We proberen juist aan iedereen die hier binnenkomt uit te leggen dat het vak van toezicht gaat over die balans tussen die verschillende kernwaarden en dat het van de context afhangt wat je wanneer moet doen. Dus soms lukt allebei en soms niet. Dus als je zorgvuldig en doortastend neemt: als je zeer zorgvuldig bent, ga je op een gegeven moment gewoon te langzaam en wordt het probleem groter omdat je niet ingegrepen hebt. En als er iemand belt met een of ander issue en je gaat er gelijk vol en doortastend op en je hebt niet nagedacht over je wettelijk mandaat, of je eigenlijk wel onaangekondigd ter plaatse mag zijn, en als je daar dan bent of je dan wel of niet aan de server mag zitten, dan wordt het een beetje ingewikkeld. En je kan wel volledig autonoom zijn, maar dan vertelt op een gegeven moment niemand je meer iets en dan zie je je informatiepositie zwakker worden en dan ben je opeens autonoom in isolatie. Dus dit zijn alle mitsen en maren die erg belangrijk zijn.

Karin en Rein: Maar nu um voorkeur.

Hanzo: Maar nu mijn voorkeur. Ik zou uiteindelijk kiezen voor 'doortastend'. Maar dat is wel met het mes op de keel, want een doortastende onzorgvuldige toezichthouder, dat is echt rampzalig. Maar ik denk dat ik zorgvuldiger ben geworden dan tien jaar geleden. Ik denk dat ik toen een grotere doortastendheidsbias had. Ik heb nu meer begrip voor het belang van een heel zorgvuldig, 
goed onderbouwd, stevig proces. Ik voel het echt. Dus als er een groot dossier voorligt dat we met ons collegiaal bestuur van vier bestuurders bespreken, dan voel ik gewoon 'Oké, nu draait het erom' en dan kijk ik echt naar alle vier de kernwaarden. En als je ze alle vier afloopt dan kijken we heel secuur: klopt het juridisch en klopt het procesmatig? Uiteindelijk draait het om publieke waarden die je probeert te creëren in de maatschappij en dus daar komt doortastendheid vandaan. Ja, ik vind het heel belangrijk dat we met voldoende onafhankelijkheid, autonomie tot ons oordeel komen, maar die verbinding is ook erg belangrijk: heb je ook echt geluisterd naar het verhaal van de ander?

Karin en Rein: $U$ maakt zelf eigenlijk al het bruggetje naar het zijn van een autoriteit. Veel markttoezichthouders zijn autoriteit. En die term 'autoriteit' heeft ook een lading, mant tegelijkertijd kan je zeggen: dat moet je verdienen. En daar spelen die kernmaarden een rol bij.

Hanzo: Ja, ik ben eraan gewend, dus voor mij heeft het niet meer die connotatie. Voor mij is het gewoon Autoriteit Financiële Markten. Het is gewoon AFM. Als ik dat hoor, dan denk ik niet 'Ah, daar komt de autoriteit'. Ik ben het met jullie eens. Je kan dat niet over jezelf stellen, maar in zekere zin heeft het ministerie van Financiën door het oprichten van de AFM dat bepaald. Dat was al zo toen ik hier kwam. We krijgen de feedback af en toe wel van 'he, wie bepaalt eigenlijk dat jij de autoriteit bent?'. Ik vind het op sommige onderdelen heel erg goed, dus ik vind dat wij de autoriteit moeten zijn als je een ingewikkeld kapitaalmarktissue hebt en het staat niet in wet- en regelgeving en je hebt daar een call nodig van mag het wel, mag het niet? Dan hoop ik dat we als autoriteit worden gezien en dat verwacht ik ook. Soms vind ik het lastig omdat 'autoriteit' ook iets heeft van 'dat is de persoon waar je heen kan gaan met een vraag en die heeft dan het antwoord' en dat is niet altijd zo. Of dat is niet altijd goed voor de markt, want wat je soms ook wilt, is dat onder toezicht staande instellingen zelf nadenken over wat vind ik eigenlijk goed en wat vind ik niet goed. En je wilt de intrinsieke motivatie aanzwengelen. Het is een dilemma en het is lastig en het mag misschien wel, maar het is eigenlijk niet goed. En het heeft onbedoelde bijeffecten op de korte of langere termijn. Tsja, weet je, dan is het makkelijk om het naar ons te duwen van, mag dit? Ja, daar moet je misschien ook zelf over nadenken, wat je wilt zijn.

Maar er zitten verschillende kanten aan. Een kant is 'mag het wel, mag het niet', een soort juridische casuïtiek. Een voorbeeld daarvan is 'Ik wil iemand een hypotheek geven en ik kom er niet uit met de loan-to-income of de loan-to-value norm en ik wil een uitzondering maken, mag het wel of mag het niet? Voldoe ik aan de uitzonderingsgronden?'. Daar zit overigens nog steeds een rol voor onder toezicht staande instellingen, maar de grenzen daarvan worden wel bepaald door de AFM. Je hebt een tweede niveau waarin je maatschappelijke problemen hebt, waar we ook wel een ander type autoriteit in zijn, bijvoorbeeld aflossingsvrije hypotheken. De helft van de hypotheken in Nederland is aflossingsvrij. Door allerlei wettelijke veranderingen is dat langzaamaan aan het dalen, maar er zit waarschijnlijk nog wel een bult in waar we meer of minder problemen mee gaan krijgen over een jaar of tien, twaalf. Voor zover we kunnen zien, is het grotendeels binnen de grenzen van de wet, maar niet alles heeft een doorlopende zorgplicht. Maar de vraag is wel: 'Wat doe je met dat probleem?'. Dus dan zie je dat de AFM ook wel een autoriteit is door het probleem te agenderen. En dan zie je vervolgens reactie komen van de Nederlandse Vereniging van Banken die waren gekomen met een campagne aflossingsblij en we gaan hier werk van maken en we gaan klanten adviseren. Dan ben je een ander type autoriteit. En het laatste niveau gaat over 'Is het financiële systeem in Nederland eigenlijk gezond en komen daar goede uitkomsten uit op de langere termijn en niet ongelooflijk veel negatieve uitkomsten waar mensen kwetsbaar op zouden worden geraakt?'. Ja, op dat niveau hebben wij een rol, maar ligt er ook een eigen verantwoordelijkheid bij de consument die z'n eigen zaken moet regelen en er ligt een verantwoordelijkheid bij het Nibud die alle normen vaststelt bij wet- en regelgeving, bij financiële partijen, dus daar zijn wij niet de autoriteit in de zin van de enige autoriteit op het gebied van duurzaam financieel welzijn.

Karin en Rein: Neem nu bijvoorbeeld dat hypotheekissue maarin de AFM faciliteert dat er een agenda en een discussie komt en hopelijk oplossingen vanuit de markt. Hypotheken, daarbij stel ik me voor dat die markt voldoende volmassen partijen heeft die dat ook maar kunnen maken, maar neem nou bijvoorbeeld FinTech, wat nog heel erg in bemeging is, waar misschien nog niet zo'n volmassen markt is. We hebben een lezing van $u$ gezien maarin $u$ inging op de vraag 'Hoe ga je om met zo'n markt in bemeging die misschien veel sneller gaat dan je je kunt voorstellen?'. U noemde met name de algoritmes en gaf best mel vergaande voorbeelden, bijvoorbeeld het voorspellen of iemand gaat scheiden of merkloos wordt.

Hanzo: Dat is al gebeurd. Ik probeerde in die lezing een prikkelend voorbeeld te verzinnen waarvan ik hoopte dat het nog buiten onze horizon zou liggen. Dat je bijvoorbeeld op basis van betaalgegevens iemand z'n kans op scheiden kan voorspellen. Het grapje is dan: 'Iemand boekt veel hotels in de buurt van zijn woonplaats en dat kan natuurlijk een trigger zijn van Goh, waarom zou je dat nou doen'. En ik had dit verhaal een paar keer als voorbeeld gebruikt en op een gegeven moment kwam iemand naar me toe en die zei: 'Ik weet al een bank die dit al doet'. Dus dat voorbeeld bestaat gewoon al, niet in Nederland, maar al wel in het Verenigd Koninkrijk als ik het me goed herinner. Het gaat gewoon heel hard. Dus trends waar we veel over nadenken, zijn digitalisering, internationalisering, individualisering. Digitalisering vanuit ons AFM-perspectief, zeker vanuit de retailkant, is natuurlijk superpositief. Als je kijkt, vroeger moest je nog in de rij staan om geld op te halen, moest je 
nog rennen omdat de bank dicht ging. En dan had je in het weekend een boterham met pindakaas omdat je geen geld had gehaald bij de bank op vrijdagmiddag om 5 uur. Als je kijkt waar we nu zijn, eerst de opkomst van geldautomaten, die nu zelf al verouderd zijn, omdat je een volledige bank op je telefoon in je broekzak hebt. Dus met mijn iPad of op mijn telefoon kan ik betalen, sparen, verzekeren, lenen en ook complexe dingen zoals aflossen op mijn hypotheek. Ik heb nu bij de bank waar ik zelf bankier, ik zal de naam niet noemen, voor het aflossingsvrije hypotheekdeel een soort hypotheekcheck. Die check is gewoon best wel goed. Je vult een aantal dingen in en dan komt er gewoon een verhaaltje uit van 'Hier moet je over nadenken' en dat is dus gewoon een algoritme dat aan het nadenken is over mijn persoonlijke financiële situatie. Als je nadenkt hoe je dat vroeger had moeten doen, dan had ik moeten bedenken dat ik die vraag had en dan had ik naar een filiaal moeten gaan en dan had ik daar over drie weken een afspraak gekregen en dan had je het alleen maar gekregen als je in de bovenste tien tot twintig procent van Nederland zat, want anders komt het niet uit. Dus de service is echt enorm hard omhoog gegaan. Maar niks is gratis in het leven, er zitten ook een paar risico's aan, dus bijvoorbeeld beïnloeding, nudging, doordat mensen ook naar betaalgegevens gaan kijken of naar het voorbeeld wat voorbij kwam dat je vormen van uitsluiting gaat krijgen op basis van gedrag uit het verleden. En nu zijn we, vooral ook met de Autoriteit Persoonsgegevens, aan het nadenken over 'Wat mag je nou met die bankgegevens?'. Daar maken we ons best wel zorgen over, bijvoorbeeld als organisaties zouden gaan afdwingen van 'Oké, je krijgt alleen maar een hypotheek als je toegang geeft tot je bankgegevens'. Of 'Oh ja, doe ook nog maar even je LinkedIn- en je Facebook-profiel'.

Ook internationalisering, merken we heel sterk. Toen ik wegging bij de AFM in 2010 was het, zeker aan de retail-kant, nog een nationaal spel. Aan de pholesalekant was de kapitaalmarkt al iets internationaler. $\mathrm{Nu}$ kwam ik weer terug en ik ben ook vrij snel naar de Europese Commissie in Brussel en naar ESMA in Parijs gegaan, gewoon om kennis te maken. En ik ben ook naar Den Haag gegaan trouwens, ik ben naar alle drie gegaan. Maar je voelt gewoon dat vanuit Brussel een belangrijk stuk van de structuur van onze wet- en regelgeving komt. En de collega's zitten elke maand twee of drie dagen bij ESMA. Dus daar voel je gewoon supervisory convergence tussen verschillende landen toenemen. Ik krijg ook steeds meer peer reviems uit Europa waarbij buitenlandse toezichthouders naar ons komen kijken hoe we het doen. Dus je voelt het Europese speelveld veel meer dan tien jaar terug.

Dit betekent dat je je voelhorens moet uitsteken om al die trends bij te houden. We zijn met een clubje mensen dat heel specifiek gericht is op die digitale en financiële technologietrends en die dat bijhouden, de diepte proberen te begrijpen en ook proberen te vertalen naar implicaties voor de AFM. Wat betekent het dan, wat moeten we dan gaan doen? Dit betekent bijvoorbeeld dat we hier een InnovationHub hebben en maatwerk.
InnovationHub betekent dat als jij denkt van 'Hé, ik heb een nieuw product, misschien moet ik iets met toezicht', dan kan je gewoon laagdrempelig bellen en dan krijg je op verschillende niveaus een antwoord waar je iets mee kan. Als je denkt van 'Hé, ik denk dat ik in het systeem pas, maar ik begrijp het niet goed en ik heb wel een heel leuk idee', dan is er voor een geselecteerde groep maatwerk en dan gaan we samen nadenken hoe we jouw product of idee passend kunnen maken in het financiële stelsel van wetgeving. Daarbij kijken we naar twee dingen specifiek: Draagt het bij aan duurzaam financieel welzijn en zitten er geen oneigenlijke risico's verborgen onder de oppervlakte. Dus we proberen te stimuleren wat helpt en te remmen wat hindert.

Karin en Rein: En stel nou, in een soort dystopisch scenario dat die data-analyse steeds verder gaat, dat bepaalde groepen mensen dus geen toegang meer kunnen krijgen tot bepaalde financiële producten. Zou dan de overheid publieke belangen moeten formuleren die bijvoorbeeld, net als bij de zorgverzekering, een soort acceptatieplicht met risicocompensatie regelen en dat iedereen een aantal essentiële diensten mel kan blijven genieten?

Hanzo: Ja, dat is primair een vraag die het ministerie van Financiën moet beantwoorden. Het is een politieke vraag. We vinden dat we als AFM best wel wat van allerlei trendontwikkelingen mogen vinden. Maar allereerst is dit denk ik een discussie voor de Tweede Kamer en het ministerie van Financiën. Maar wat wij zeker zullen doen is het agenderen, dus als we het mis zien gaan, van 'We zien in toenemende mate dat er sprake is van uitsluiting en dat mensen buiten de boot vallen', dan zullen we zeker lawaai gaan maken en zeggen van 'Dit gaat niet goed, hier moet wat aan gebeuren'. Dus zo zou ik de rol van de AFM zien. Als je naar mijn persoonlijke mening vraagt, dus geen AFM-standpunt, van wat vind ik logisch, dan vind ik, en dat is denk ik ook wel breed maatschappelijk gedeeld, dat je toegang moet hebben tot financiële basisvoorzieningen. En dat zie ik ook wel in allerlei VN-verdragen staan. Ik heb een tijdje voor de Wereldbank gewerkt als adviseur en in Lesotho en in Zambia; daar hebben we heel hard gewerkt aan financial inclusion. Dat mensen toegang krijgen tot een bankrekening, tot ziektekostenverzekering, tot eenvoudige leningen als ze moeten sparen voor zaaigoed zodat ze een jaar later weer kunnen oogsten. Als je naar de financial inclusion statistics kijkt in Nederland, die zijn echt ontzettend goed. Bijna 99 procent van de mensen heeft hier toegang tot financiële basisvoorzieningen. Het zou een beetje raar zijn dat door ons fantastische datagedreven toezicht over 10 jaar opeens 20 procent van de bevolking zonder bankrekening en zonder zorgverzekering zou zitten.

Karin en Rein: $U$ heeft net uitgebreid verteld over twee trends, digitalisering en internationalisering, maar nog niet over de derde: individualisering. Hoe ziet u dat terug?

Hanzo: Waar je het heel duidelijk ziet, is natuurlijk de langetermijntrend bij pensioenen. Dus de trend op hoofdlijnen zouden wij duiden als: vroeger waren er 
heel veel collectieve voorzieningen en verzekeringen. Je ziet dat dat individualiseert, dat dat meer van jouw individu afhangt. Je ziet het bij de arbeidscontracten dat vroeger iedereen in loondienst was, tegenwoordig is het hybride: ook zzp en misschien ook nog een stukje loondienst. Dus daar zie je dat mensen wat vaker van baan of van carrière wisselen, dus daar zie je meer individuele paden. Pensioenen is het meest duidelijk als je 30 jaar terug kijkt en als je 30 jaar vooruit kijkt. Het stelsel was vroeger sterk collectief en nu krijg je een soort hybride variant waarin ik zou verwachten dat als je 30 jaar vooruit kijkt, dat het niet collectiever wordt, maar eerder individueler. En dat betekent nog wel wat. Een pensioencontract zat ergens tussen uitgesteld loon en een financieel product in en dat begint te verschuiven. Het begint steeds meer karakteristieken van een financieel product te krijgen en dus wordt het steeds belangrijker dat jij goede informatie hebt en dat je zelf meer te kiezen hebt. Oké, dat klinkt heel leuk en goed en positief: 'Ik kan meer kiezen'. Of ik nu 10 procent eruit wil trekken bij de start van mijn pensioen, oké, maar heb je door hoe je levensverwachting eruit ziet? Heb je door hoeveel per jaar je dan minder krijgt? Heb je door wat verstandig is of onverstandig is? Dus de rol voor de AFM wordt groter als je meer individuele, persoonlijke verantwoordelijkheden krijgt voor je eigen financiële toekomst.

Karin en Rein: Tot slot zouden me graag willen weten welke estafettevragen u aan Martijn Snoep van de Autoriteit Consument en Markt zou millen stellen.

Hanzo: Ik ben wel heel benieuwd wat volgens Martijn elementen of onderdelen van een goede toezichtstrategie zijn. Hoe ziet dat er nou uit? Wat hoort erbij en wat hoort er nou niet bij? En - mocht hij die voor de ACM al hebben ingevuld - hoe ziet die toezichtstrategie er voor de ACM uit? Dat vind ik interessant om te weten. En ik ben ook wel benieuwd hoe hij nadenkt over de balans tussen handhaven en beïnvloeden.

Karin en Rein: Bedankt voor dit gesprek. 